\title{
AN ANALYSIS OF SUBJECT AGREEMENT ERRORS IN ENGLISH: THE CASE OF THIRD YEAR STUDENTS AT THE NATIONAL UNIVERSITY OF LESOTHO
}

\author{
Mampoi Irene Chele
}

\begin{abstract}
The purpose of the paper is to study the linguistic environments in which subject-verb agreement errors occur in students' academic work. The paper also aims to find out if these errors were competence or performance errors. The study was conducted at the National University of Lesotho (NUL).

The study had a two stage research design. In the first stage, students wrote a test in their field of study. In this test, no focus on subject-verb agreement was included. The test scripts were used to identify subject-verb agreement errors and the linguistic environments in which such errors occurred. In the second stage, a follow up test was given to the same group of students. They were given sentences which were a mixture of correct, incorrect and ambiguous sentences and were asked to evaluate the grammaticality of the sentences by putting a tick after the correct sentences and a cross after the incorrect ones. For the incorrect sentences they were to underline the error and give the correct answer. The main findings of the study were: subject-verb agreement errors are prominent in simple sentence constructions and in complex linguistic environments. The study also found that performance errors appear frequently in simple sentence construction (simple errors) while competence errors are found to be prominent in complex linguistic environments.
\end{abstract}

http://dx.doi.org/10.4314/gjl.v4i1.3

\section{Introduction and Background}

"Every time Obama opens his mouth, his subjects and verbs are in agreement," says Mr. Logsdon, "If he keeps it up, he is running the risk of sounding like an elitist” (Borowitz 2008).

Error free use of language is important. If all that was important was to make oneself understood, it would be easier to decide which mistakes mattered. However, writers are judged by grammatical correctness. Hudson (1999) emphasizes that it is important 
to write grammatically for reasons of face, of respectability. Incorrect grammar gives a negative impression of the writer.

Lesotho is one of the countries where English is used as one of the two official languages. Due to this fact, English has gained prestige in the country and is therefore introduced as early as pre-school. However, these children only get exposed to English when they are in school. Back home and in meetings with friends outside school, communication is done in the first language, Sesotho. English has gained such high status that it has become one of the preliminary requirements for students' entry into the National University of Lesotho. According to the requirement, an applicant should have passed English with credit. With such high caliber of students, one would expect that grammatical errors would have been eliminated at high school. There is, however, continuing prevalence of a wide range of errors in students' writing. Lecturers, especially those who teach communication skills, receive endless complaints from lecturers in other courses about the incorrect grammar that is reflected in students' writing. The kinds of errors that students make are frequently subject-verb agreement errors. Typical agreement errors as found in a pilot study prior to this study are:

- He want to pass the message but in a short form

- He or she know that they will listen

- The speaker can create new texts which reminds people of other texts that were written before

In English, as in many other languages, one of the grammar rules is that the subjects and the verbs must agree both in number and in person. Subject-verb agreement therefore refers to the matching of subjects and verbs according to their number (Greenbaum and Nelson 2002: 141). This means that a singular subject must be matched with a singular verb form: the child cries, and a plural subject must be matched with a plural verb form: the children cry. Quirk (1973: 176) elaborates that there are, however, many special and difficult cases relating to this rule. The complexity is especially reflected when there are words and phrases intervening between subjects and verbs. Examples:

- The dishes in the kitchen is/are dirty

- The reason for the decline in Basotho working in South Africa mines is/are that mines are closing down. 


\section{The Concept of Error}

The concept of error is very problematic in that there is no single definition that could be said to apply in all situations. This is because nowadays the concept of 'World Englishes' has developed. This means that English is used in many parts of the world and by many people who are not native speakers. As a result, there are different varieties accepted in different speech communities. Corder's (1974: 260) definition of error as "the use of a linguistic item in a way which a fluent native speaker of the language regards as showing faulty or incomplete learning" may not be considered comprehensive as the native speaker cannot be used as the only model anymore. The study therefore prefers the following working definition: An error is a form of English which is unacceptable in a particular speech community, representing deviation from the standard which is taught in that community. For example, British and American standard varieties of English differ. Corder (1974: 25) distinguishes between performance errors which are once off violations of grammatical conventions and competence errors which are consistent in an individual's speech or writing and indicate an internalized system different from that of a target language. In other words, the individual does not know how to use the correct form. Fisiak (1981: 224) says performance errors are deviances due to factors such as memory limitations or fatigue and they can be self-corrected when attention is drawn to them.Similar studies have been done to address this topic elsewhere. For example, Bock and Miller (1991) studied subject-verb agreement errors in speech. They had realized that the rule that says subjects and verbs in English must agree in number is sometimes violated in sentences such as the cost of the improvements have not yet been estimated. They examined whether the incidence of such errors was due to the plural noun phrase or was dependent on whether the noun phrase was animate, or if it was caused by the fact that the utterance is lengthy and consequently separates the verb from its subject. Data was collected from English native speakers at Michigan State University. The study found that errors were most likely when a nominal post modifier separated the head from the verb and the number of the noun nearer to the verb differed from that of the head noun. Errors were most likely to occur when the head noun was singular and the local noun plural. The occurrence of agreement errors was not affected by the length of the post modifier. Errors were just as frequent after the bridge to the islands as they were after the bridge to the popular coastal islands.Pittman (2005) embarked on a similar study of subject verb agreement errors. The main reason for conducting the study was to investigate whether a non-subject or local noun that is also a plausible subject for the verb will cause more agreement errors than an implausible local noun. In other words, she wanted to find out if the boy near the dogs is/*are running away will cause more errors than the boy near the trees is/*are running away. 
The difference between the two sentences is that in the first sentence the subject and the local noun can both do the action of running while in the second sentence the local noun tree cannot do the action of running. The study found that a non-subject that is also a possible subject caused more agreement errors than an implausible local noun. That is, the boy by the trees is/*are tall caused more errors than in a sentence that reads, the baby under the blankets is/*are young.

The main focus of the above articles was to find the influence of the post-modified subject, which is one of the linguistic environments which increased the likelihood of agreement errors. This paper, (through the method that was used) was able to come up with not only the post-modified subject as a possible factor in agreement errors, but it was also designed to reveal any other linguistic environments which possibly influenced students into making subject-verb agreement errors. The other direction which the paper took was to try to find out if the agreement errors were a result of carelessness, which would classify them as performance errors, or if they occur because students simply do not know the correct form, which would classify such errors under competence errors.

\section{Methodology}

The study had a two-stage research design. The first stage involved the identification of subject-verb agreement errors in students' writing and the linguistic environments which affect such errors. In the second stage, the same students were given an exercise which was meant to provide evidence of which errors in the first stage were performance or competence errors.

\section{First Stage}

Data was collected from third year Historical Studies students in the National University of Lesotho. All the 55 students who were doing an elective course titled 'Environment and Conservation in Africa' were used as research subjects. The study deliberately chose students who are doing this course because, unlike many Historical Studies courses which report their events in the past tense, this particular course is reported in the present tense because it relates to issues which are occurring in the present, even though the past has a bearing on them. Subject-verb agreement applies mainly to present tense verbs.

The students wrote a test in their field of study. In this test, no focus on subject-verb agreement was included. The test scripts were used to identify subject-verb agreement errors and the linguistic environments in which such errors occurred. All subject- verb errors were recorded according to their script number. The names of the owners of the scripts were deleted and substituted with numbers according to the order in which they appeared. This was done so that the subjects' names could remain anonymous. 
As each script was analysed, a comment was made on any factors in the linguistic environment that appeared to have contributed to each agreement error. The scripts were thereafter returned to the concerned lecturer so that she could proceed with the marking of the test.

\section{Second Stage}

In the second stage, a follow up test was given to the same group of students. This time the number was 41 , as some had failed to attend the class. Thirty sentences were picked from the test they wrote. These sentences were a mixture of correct, incorrect and complex or ambiguous sentences. There were 11 sentences without errors, 15 sentences with subject-verb agreement errors and 4 complex/ambiguous sentences. The incorrect sentences which were picked were the ones which had types of agreement errors which were found to be common in many scripts. The incorrect sentences were the main target; they were meant to see if the students could recognize the error and correct it. With the ambiguous sentences, the purpose was to see if the students could correct them despite their ambiguity. The correct sentences were used as distracters. The exercise was given to students and they were asked to evaluate the grammaticality of the sentences by putting a tick after the correct sentences and a cross after the incorrect ones. For each of the incorrect sentences, they were asked to underline the error and give the correct answer. No attention was drawn to subject agreement.

\section{The Findings}

Subject verb agreement errors are prevalent in students' writing. There are several linguistic environments that appear to contribute to this high rate of errors. Many subject-verb agreement errors that students made can be classified as simple errors. The simple errors are directly related to the inappropriate omission or addition of the third person inflection. Celce-Murcia and Larsen Freeman (1983: 36) confirm that the subject-verb agreement poses a problem mainly in the present tense, where the third person singular forms are inflected while others are not. Leech (1994: 262) asserts that some learners view the third person singular number as "troublesome, tantamount to slip of the tongue and lengthens the word and pronunciation" and wish they could be allowed to omit it. Another source of error found in students' writing emanates from words that come between the subject and the verb, especially when such words do not agree in number with the main subject of the sentence. In sentences such as an example of living things are mountains, many students chose the verb that agrees with the noun nearer to it. Leech (1994: 262) classifies this error as an error of attraction. He says this is a situation where the verb tends to agree with the noun or pronoun that closely precedes it. He calls this feature 'attraction' or 'proximity' because the last 
noun attracts a certain form in the verb and upsets the subject verb agreement rule. There were also errors which occurred in an environment where there is usage of a collective noun such as 'community' or indefinite pronoun such as 'everyone' everybody' 'every individual' and 'each and every'. The traditional prescription maintains that singular subject-verb agreement applies in such cases because 'each' and 'every' (one) are grammatically functioning as singular subjects. Problems concerning the correct usage of subject-verb agreement arise because the collective nouns and indefinite pronouns are conceptually plural but grammatically singular. Celce-Murcia and Larsen Freeman (1983: 44) argue that the reason for the problem is that subject-verb agreement has both syntactic and semantic aspects. There is therefore potential conflict when a form is syntactically singular but semantically plural or vice versa.According to the collected data, subject-verb agreement is especially problematic when there is a subordinate clause in a sentence structure. Students seemed to struggle with the referent of the relative pronoun 'which' when it introduces a subordinate clause. There is uncertainty as to whether the pronoun 'which' refers to the immediate noun or the initial noun that began the sentence. Greenbaum and Nelson (2002: 179) explain that a relative pronoun describes the noun that immediately comes before it and that such a pronoun is singular or plural depending on the noun it refers to. However, students referred to an incorrect noun phrase. Example: This is one of the factors which encourages people to impact the environment negatively. The students have interpreted the referent of 'which' to be 'one' and not 'factors' as it should be. The research subjects in this study seemed to have a problem in identifying a specific noun that the pronoun 'which' refers to in a clause and may sometimes be attempting to use it to refer to the whole preceding clause. For example: Natural resources are faced with the problem of pollution and exhaustion which in turn becomes dangerous to human lives. This attempt to use 'which' to refer to the whole clause sometimes leads to the wrong choice of subject verb agreement.

\section{Performance versus Competence Errors}

The following table shows the number of errors interpreted as performance and competence errors. This was done through counting how many students corrected the error when they saw one, and how many recognized a well-constructed sentence. It is assumed that performance errors appear in constructions where most students have corrected the errors while competence errors appear in constructions where only a small number of students have noticed and corrected the errors.

\begin{tabular}{|l|l|}
\hline PERFORMANCE ERRORS & COMPETENCE ERRORS \\
\hline 15 & 13 \\
\hline
\end{tabular}


According to the data above there is an almost equal number of performance and competence errors. This shows that subject-verb agreement errors are very common in students' writing, and that depending on the linguistic environment they are faced with, they may make errors that may be due to performance or to lack of competence. Performance errors seem to be mostly reflected in correct sentences. This shows that students are able to recognize a grammatical sentence even if they do not always construct their own. This in turn shows that comprehension comes before production, as proved by O'Grady (1996: 466) when he says people's ability to comprehend language is more advanced than their ability to produce sentences of their own. In correction of incorrect sentences, performance errors are also realized in simple constructions where there is no specific linguistic environment which seems to be affecting the error (simple errors). This then helps the researcher to conclude that in simpler constructions and in sentences which are already correct, the majority of the students are able to use or recognize the correct form of the verb. However, due to carelessness, and lack of habitual checking of subject-verb agreement in sentence constructions, some students still make errors.Competence errors seem to be prominent in linguistic environments such as the following:

- Where the subject is coordinated;

- Where the subject is post modified;

- Where the sentence has a subordinate clause that begins with a relative pronoun 'which';

- Where the subject is an indefinite pronoun;

- Where there are plural nouns coming after the verb;

- Where the subject is a mixture of both coordination and post modification.

These findings are similar to the findings in the study which was done by Bailis (2006). It found similar linguistic environments which increase the possibility of subject-verb agreement errors. The collected data provide evidence that in quite complex linguistic environments, subject-verb agreement becomes a challenge to students, but in simpler constructions they are able to recognize or construct a well formed sentence with subjects and verbs in agreement. Errors that are made in these simpler constructions are likely to be through carelessness and could be done away with if students could proof read their work effectively. The failure to notice simple errors still has to do with the fact that students are careless and overlook things.

\section{Summary of Findings}

The students in the department of historical studies who are doing a course titled 'Environment and Conservation in Africa' seem to encounter serious problems when it comes to the construction of grammatical sentences with subjects and verbs in 
agreement. Out of the 55 scripts that were analysed only 7 scripts were free from subject-verb agreement errors. Most of these errors were simple errors, but other errors seemed to be influenced by specific linguistic environments such as: post modification, relative pronouns, starting the sentence with 'there', nouns after the verb and indefinite pronouns occupying the subject position. The students appeared to be easily distracted by the words that separate the subject and the verb. Moreover, the relative pronouns that are used to begin a subordinate clause posed a problem to students; they did not know which noun the relative clause referred to and as a result made subject-verb agreement errors. Another contributory factor involved the position of the subject in a sentence; if the subject was postponed, as in a sentence that starts with 'there' or 'here', the students could not easily identify the subject and therefore made errors. Also, nouns such as collective nouns and indefinite pronouns cause errors when they occupy the subject position because they are semantically plural but are grammatically singular. Performance errors were mostly realized in sentences which were already correct and in simple sentence constructions where no specific linguistic environment is recognized. However, competence errors seemed to appear where the subject-verb agreement was found in complex linguistic environments. Looking at the two stages of data, it can be concluded that subject verb agreement errors are found in simple sentence constructions and in complex linguistic environments. Some of these errors are performance errors while others are competence errors. Time pressure, carelessness and lack of habitual proof reading of one's work lead to performance errors; however, lack of sufficient knowledge of subject-verb agreement rules consequently leads to competence errors. The study has shown that subject-verb agreement is a problem for learners even at the higher level of study. Sometimes they know what they are doing but are just careless. There are, however, instances where the students do not seem to know what the correct form of the verb should be.

\section{Conclusion}

Firstly, this paper intended to find the linguistic environments in which subject verb agreement errors occur. Based on the findings, the paper concludes that subject-verb agreement errors are increased by linguistic environments such as; post modified subject, relative pronoun 'which', collective noun, reversed order or 'there' + verb construction, indefinite pronoun and nouns after the verb. Some errors are simple; there is no linguistic environment that seems to have influenced the error.The other objective of this paper was to find out if the agreement errors that students make are performance or competence errors. According to the findings, students make both performance errors and competence errors. The paper therefore concludes that due to carelessness and/ or stress students make performance errors. Fisiak (1981: 224) says 
performance errors are deviances due to factors such as memory limitations or fatigue, and can be corrected if attention is drawn to them. Other errors, however, are competence errors which appear to be influenced by a complex linguistic environment. These errors emanate from insufficient knowledge of verb agreement and indicate an internalized system different from that of a target language.

\section{Recommendations}

There is a need for teachers and lecturers to be made aware of the difference between performance and competence errors so that appropriate measures can be taken to help eliminate these subject- verb agreement errors. It is also important to train tertiary level students in proof reading. The study has discovered a possible source of error which does not seem to have been mentioned by other researchers. This has to do with the influence of the relative pronouns, which have contributed to students' making errors. I therefore strongly recommend that another study on subject-verb agreement could be carried out but this time with special focus on the influence of the relative pronoun. If all these suggestions are taken into account, perhaps, the prevalence of subject-verb agreement errors might decrease.

\section{References}

Bailis, L., 2006. Study of writing errors: subject verb agreement. Viewpoints 7.2: 110-113.

Bock, K. C. and A. Miller, 1991. Broken agreement. Cognitive Psychology 23: 45-93.

Borowitz, A., 2008. http://www.huffingtonpost.com/andy_borowitz/obama-use-of-completese_b_144642.html (accessed 23 November 2008).

Celce Murcia, M. and D. Larsen Freeman, 1983. The Grammar Book. Rowley Mass: Newbury House.

Corder, P., 1974. The significance of learner's errors. International Review of Applied Linguistics 9. 2: 161-171.

Fisiak, J., 1981. Contrastive Linguistics and the Language Teacher. Oxford: Pergamon Press. Greenbaum, S. and G. Nelson. 2002, An Introduction to English Grammar. London: Longman.

Hudson, R., 1999. Subject verb agreement in English. English Language and Linguistics 3. 2: 173-207.

Leech, G., 1994. A Communicative Grammar of English. London: Longman.

O'Grady, W., M. Dobrovilsky and M. Katamba, 1996. Contemporary Linguistics. London: Longman.

Pittman, C. M., 2005. The effect of the predicate on agreement error rates. Toronto Working Papers in Linguistics 23 2: 115-146.

Quirk, R., 1973. A University Grammar of English. London: Longman Group Limited. 